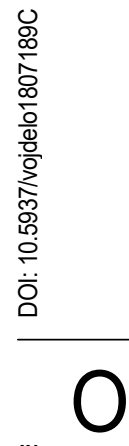

\title{
PROBLEMI ZAŠTITE LICA BEZ RODITELJSKOG STARANJA
}

\author{
Milenko Čurović \\ Visoka škola socijalnog rada, Beograd
} se zadovoljiti gotovo isključivo u porodici. Socijalna zaštita, kao organizovana društvena delatnost, u određenim situacijama, pored svoje uloge da u zajednici sa porodicom omogući ostvarenje njenih funkcija, mora ponekad i da preuzme, odnosno kompenzuje neke funkcije porodice.

Odsustvo porodičnog staranja za decu znači odsustvo bliskog, direktnog kontakta odnosno emotivne veze sa roditeljima ili onima koji vrše ulogu roditelja u okviru prirodne porodice.

Ključne reči: porodica, roditelji deca, socijalna zaštita, društvo

\section{Uvod}

Dorodica, kao primarna društvena grupa ili institucija, je predmet proučavanja svih društvenih nauka. Postoji više pristupa i različitih definicija pojma porodice. Poći ćemo od definicije u kojoj se „pod porodicom u širem smislu podrazumeva ukupnost socijalnih, ekonomskih i personalnih odnosa koji nastaju između grupe osoba povezanih po osnovu srodstva, koja se kao konkretna grupa jasno razgraničava od ostalih sličnih jedinica u društvu“" i posebno posmatrati odnose roditelja i dece i odrasle dece i njihovog roditelja koko bi osnovni pravac našeg interesovanja - odsustvo porodičnog staranja i socijalno-zaštitno reagovanje društvene zajednice, što je moguće, bolje razumeli i dali doprinos njegovom razvoju.

Osnovna i glavna posebnost porodičnih odnosa je osećanje ljubavi, vredan ljudski kontakt koji međusobno povezuje roditelje i decu, članove porodice. Potreba deteta za sigurnošću i prisnim odnosima može se zadovoljiti gotovo isključivo u porodici. Ova potreba karakteristična je i za starost a ne samo detinjstvo i takođe se zadovoljava uglavnom u porodici.

U adaptiranim porodicama, u kojima je uravnotežena osnovna kontraverza ili protivrečje da li deca treba da budu žrtva roditelja ili roditelji žrtve dece u kojima ni jedna ni druga generacija svoj deo aktivnosti u funkcionisanju porodice ne prihvata kao žrtvu nego kao neophodnu potrebu zasnovanu na međusobnom osećanju poštovanja i ljubavi, sve potrebe i dece i roditelja zadovoljavaju se bez međusobnog većeg osećanja lišenosti ličnih, uslovno rečeno, prava.

\footnotetext{
${ }^{1}$ Anđelka Milić i grupa autora; „Domaćinstvo, porodica i brak u Jugoslaviji“, Institut za sociološka istraživanja, Filozofskog fakulteta u Beogradu, Beograd, 1981.
} 
Ali, postoje i porodice sa odnosima suprotnim navedenim, čak takvim odnosima koji pojedine njihove članove ili decu ili stare dovode u stanje lišenosti porodičnog staranja. Tada je reagovanje društvene zajednice, sa ciljem kompenzacije porodičnih funkcija, neophodno.

Odsustvo porodičnog staranja može značiti kako odsustvo adekvatnog ispunjavanja, od strane porodice, neke od njenih funkcija pojedinačno ili nekoliko njih, a može značiti i odsustvo izvršenja svih porodičnih funkcija. Tako, dakle, možemo govoriti o odsustvu adekvatnog porodičnog staranja, odnosno potpunom odsustvu porodičnog staranja.

Da navedemo osnovne funkcije porodice, onako kako se one u literaturi o porodici navode:

- Biološka - reproduktivna

- Vaspitna - kulturna

- Ekonomska - proizvodna ili potrošačka

- Pravna - zaštitna

- Socijalna - zaštitna i

- Zdravstvena - zaštitna.

U zavisnosti od stepena razvoja društvene zajednice pojedine funkcije porodice imaju odliku dominantnosti kao što su i pojedine funkcije porodice više ili manje podruštvljene. U savremenim, razvijenim društvenim zajednicama prisutno je i podruštvljavanje ekonomske funkcije (posebno proizvodne sfere), vaspitno - kulturne, kao i pravne, zdravstvene i socijalno - zaštitne funkcije porodice. I u našoj društveno - političkoj zajednici ove funkcije porodice su svakako podruštvljene, odnosno, u velikoj meri društvena zajednica u saakciji sa porodicom ostvaruje sve ove funkcije.

Određene organizovane oblasti društvenih delatnosti kao što su predškolsko vaspitanje, obrazovanje, zdravstveno, pravne institucije i socijalna zaštita su delatnosti koje preuzimaju u određenoj meri u ime društva aktivnosti u ispunjavanju vaspitno - kulturne, zdravstvene, pravne i socijalno - zaštitne funkcije porodice. Udeo porodice u ispunjavanju ovih funkcija se promenio ali ne i izgubio. Govorimo dakle o podruštvljavanju porodice.

Socijalna zaštita, kao organizovana društvena delatnost, međutim, u određenim situacijama, pored svoje uloge da u zajednici sa porodicom omogući ostvarenje njenih funkcija, mora da preuzme, odnosno kompenzuje, sve funkcije porodice (razume se sem biološko - reproduktivne). Tada ne možemo govoriti o podruštvljavanju porodice u onom smislu da podruštvljavanje znači „... delimično prenošenje porodičnih funkcija na društvo, s tim što u obavljanju ovih funkcija učestvuju zajedno i porodice i društvene institucije, a u međusobnim odnosima čija jačina, umerenost i raspodela moći među njima može da učvršćuje ili da menja kako porodice tako i date društveno - političke sisteme ${ }^{\text {“2 }}$, nego o jednom posebnom vidu prenošenja na društvenu zajednicu, odnosno socijalnu zaštitu potpune brige o jednom delu dece i omladine i sa druge strane odraslih i starijih građana koji su u situaciji potpunog odsustva porodičnog staranja.

Socijalna zaštita se, dakle, od drugih društvenih delatnosti, koje svojom aktivnošću podruštvljavaju porodične funkcije, razlikuju time što predstavlja u ovom određenom segmentu, brige o korisnicima lišenih porodičnih staranja, delatnost koja institucionalizuje porodicu odnosno kompenzuje u potpunosti sve njene funkcije. Naravno i socijalna zaštita kao društvena delatnost ima za cilj da u okvirima socijalne politike, pre svega, porodici pomaže u njenom uspešnom funkcionisanju te je većina oblika, mera zaštite kao usluga orijentisana u tom pravcu, ili bi tako trebalo da bude.

\footnotetext{
${ }^{2}$ Olivera Burić i grupa autora: „Porodica i društveni sistem“, Institut za socijalnu politiku, Beograd, 1980.
} 
U zaštiti dece i omladine i odraslih i starih bez porodičnog staranja, kada su u pitanju one grupacije korisnika vezanih za porodice koje ne ispunjavaju neku od svojih funkcija, pravce zaštite treba usmeriti ka oživljavanju tih funkcija porodice i ostaviti veoma malo prostora onim oblicima zaštite kojima se moraju okupirati sve funkcije porodice. Dakle i socijalna zaštita je delatnost kroz koju se, pre svega, određene porodične funkcije podruštvljavaju $s$ tim što je jednim delom svojih aktivnosti i oblast institucionalizacije porodice.

Ako smo utvrdili da se uglavnom u porodici mogu ispuniti potrebe i dece i starih za osećanjem ljubavi, prisnosti, sigurnosti i poštovanja, lako ćemo doći do zaključka s jedne strane, koliko je važno kroz sve oblike društvenog reagovanja pa i kroz socijalno - zaštitnu delatnost pružiti podršku porodici u njenom funkcionisanju, a sa druge strane, koliko je značajna i veoma složena delatnost socijalne zaštite, kada u određenim situacijama mora da kompenzuje sve funkcije porodice.

Odsustvo porodičnog staranja razlikuje se po intenzitetu u tom smislu koje se sve funkcije porodice ne ostvaruju u potrebnoj meri. Od toga zavise načini reagovanja u okvirima socijalne zaštite. Moramo napraviti razliku i u značaju odsustva porodičnog staranja u odnosu na decu i omladinu s jedne strane, i starijih građana sa druge strane.

Osnovna razlika je u tome što za decu odsustvo porodičnog staranja znači odsustvo bliskog, direktnog kontakta odnosno emotivne veze sa roditeljima ili onima koji vrše ulogu roditelja u okviru prirodne porodice, a za starog, odsustvo neposrednog kontakta sa svojom decom ne znači i odsustvo osećanja bliskosti i emotivne veze. Ova razlika, razumljivo, proističe iz različitih prirodnih karakteristika i potreba različitih životnih dobi, te i odsustvo porodičnog staranja, naročito ono kog označavamo potpunim, ima različitu težinu. Ovo se, naravno, ne sme shvatiti kao različito davanje značaja organizovanom reagovanju društvene zajednice na odsustvo porodičnog staranja u odnosu na decu i omladinu i sa druge strane, u odnosu na odrasle i stare. Naprotiv, znači pokušaj usmeravanja reagovanja socijalne zaštite na odsustvo porodičnog staranja kao jedinstven problem i mladih i starih, sa namerom ukazivanja na posebne teškoće i složenost socijalno-zaštitnih aktivnosti vezanih za decu koja ne mogu rasti i razvijati se u svojim prirodnim porodicama.

\section{Ciljevi zaštite}

Razmatranje ciljeva zaštite treba da nam omogući, pored ostalog, i stvaranje dobrih osnova - kriterija za prestanak i obustavu angažovanja organa starateljstva, centra za socijalni rad. Svaki postupak ili aktivnost mogu da se približavaju realizaciji nekih postavljenih ciljeva, ili njihovim pojedinim elementima, da ih ostvare u većoj ili manjoj meri, ali i da idu mimo postizanja zadatog ostvarenja interesa korisnika usluga. Reagovanje na trenutne okolnosti i situacije jednokratnim uslugama, može da stvara privid o uspešnoj zaštiti i ostvarivanju zadataka i ciljeva. Takav je slučaj kada se posredstvom organa starateljstva otkloni pojedinačna smetnja ili pojedinačni rizik, recimo, ostvarenje penzije za ostarelog čoveka lišenog porodičnog staranja. Ovim se ne želi umanjiti i osporavati značaj takvih pojedinačnih akcija, već isključivo napraviti potrebna razlika između ostvarivanja pojedinačnih, posebnih ciljeva i opšteg cilja. Poštovanje već istaknutog principa potpunosti delovanja najneposrednije iziskuje ovo razlikovanje.

Izvesno je da se opšti cilj - pomoć do samopomoći ne može ostvarivati bez realizacije posebnih ciljeva. U oblasti zaštite odraslih i ostarelih građana lišenih porodičnog stara- 
nja, moramo prihvatiti činjenicu da se ovo optimalno rešenje ne može ostvariti u sledećim slučajevima:

- Sve dok se ostvaruje pravo u koje je korisnik usluga uveden ovlašćenjima organa starateljstva (osnovna novčana naknada, tuđa pomoć i nega, domski smeštaj i starateljska zaštita);

- Kada nisu ispoštovani osnovni principi zaštite, pa su nastupile ireverzibilne posledice i onemogućile ostvarenje opšteg cilja i kada ispad psihofizičkih funkcija nije moguće prevenirati, niti otkloniti, a on je takovog značaja da onemogućava postizanje opšteg cilja. Takođe, opšti cilj nije moguće postići ako se ne izvrši pozitivna promena određenih bitnih stavova dece i odraslog, ostarelog člana porodice (o kome je reč), a u odnosu na zajedničko življenje, ne retko lečenje i rehabilitaciju.

Ova nabrajanja nedvosmisleno sužavaju mogućnosti za ostvarenje opšteg cilja i neposredno ukazuju na složenost prirode problema o kome je reč. Možemo da zaključimo, da je u svim navedenim situacijama delovanje centra za socijalni rad nužno definisati na nivou dostignuća posebnih ciljeva zaštite. Na primer, stav ostarelog građanina, koji je inače poslovno sposoban, da hoće isključivo domsku zaštitu, je činjenica koja određuje i nivo postignuća cilja (ukoliko se stav ne izmeni).

Opšti cilj je moguće postići: obezbeđenjem uslova za ostanak u prirodnoj sredini, smeštajem u porodicu srodnika ili drugu porodicu; realizovanjem usluga posredovanja uz postizanje svih osnovnih principa zaštite, kada izostaje značajan ispad psihofizičkih funkcija (ne odnosi se na domski smeštaj) i pozitivnom promenom stava odrasle dece i odraslog, odnosno ostarelog člana porodice o kome je reč. U svim ne nabrojanim situacijama opšti cilj je moguće sam delimično postići.

Ova pravila valja ugrađivati, kako u dijagnostički postupak, tako i u dijagnostički zaključak, da bi se ona sadržala u planu zaštite, to jest u delu koji se specifično odnosi na ovu materiju. Ova izjašnjenja u dijagnostičkom zaključku predstavljaju kriterijum za ocenu uspešnosti tretmana, njegovo trajanje i njegov prestanak. Karakterističan je podatak da u posmatranom periodu zadnjih pet godina, u oblasti domske zaštite ostarelih građana u Beogradu, nije planiran ni jedan otpust. Ova činjenica se bitno suprotstavlja definiciji ovog oblika zaštite koji se obično označava kao privremeni smeštaj. Možemo, dakle, smatrati da trajanje smeštaja određuju stav korisnika ili prestanak životnih funkcija. Ipak, period od pet godina posmatranja nije dovoljno pouzdan da bi se izneo zaključak, koji bi bio opšte važeći, čak i za praksu u Beogradu. Da ne bismo razrešavanje potreba i prestanak tretmana prepuštali slučaju, uvek smatramo da je obaveza organizatora zaštite, pored ostalog, i planiranje prestanka, odnosno obustave tretmana gde i kada je to moguće.

Treba napomenuti da su posebni ciljevi usmeri na kompenzovanje pojedinih statusa, da ih je, kada su realno postavljeni, moguće ostvariti poštovanjem osnovnih principa zaštite u okvirima adekvatnog modela spoljašnje saradnje. Sasvim je razumljivo da je postavka valjda dijagnostički zaključak i adekvatan plan zaštite za odraslog, odnosno ostarelog korisnika usluga.

\section{Principi zaštite}

Princip blagovremenosti delovanja. Ako iz metodološko praktičnih razloga celokupnu zaštitu grubo podelimo na otvorenu i zatvorenu, primena principa blagovremenosti i realizaciju postavki koje iz toga proističu, situiramo na sledeći način: u oblasti zatvorene zaštite, 
odnosno domskog smeštaja možemo govoriti o treće nivou blagovremenosti. Reč je dakle o najmanje poželjnom nivou realizovanja ovog principa. Izuzetak od ovog pravila predstavlja primena domskog smeštaja u modelu zaštite, kada je on, inače, ostvarivan uz prethodno poštovanje svih principa zaštite; ovo u slučaju kada je korisnik usluga, zbog pada psihofizičkih funkcija i psihofizičkog statusa, neminovno u situaciji da mora napustiti prirodnu sredinu. To znači da je ostao bez porodičnog staranja ne nebrigom članova porodične grupe (njih nema ili su objektivno onemogućeni da se staraju o njemu), da nije reč o odsustvu blagovremenog angažovanja organa starateljstva i da su, prethodno adekvatnim nastojanjima, iscrpljeni svi oblici u otvorenoj zaštiti, pa i smeštaj u drugu porodicu.

U oblasti otvorene zaštite nije uvek moguće, u potpunosti, ispoštovati princip blagovremenosti jer postoji niz razloga i situacija koje to sprečavaju. Takav je na primer problem formiranja adekvatnog i blagovremenog „znanja o“ nastojanju ili već postojećem stanju, bilo uslova statusa, koje kompromituje poštovanje principa blagovremenosti. Takođe je poznato da korisnik usluga, a i članovi porodične grupe, po pravilu, ne opažaju nastojanje, pa ni relativno jasne znake duševnog oboljenja. Problem predstavlja i delovanje određenih stavova i predrasuda koje usporavaju ili onemogućavaju blagovremen transfer ovakvih značajnih informacija. Iz ovih, a i drugih razloga, organ starateljstva, uz najbolju organizaciju svoga rada i zalaganja, nije uvek u mogućnosti da blagovremeno reaguje, jer naprosto ne poseduje potrebne informacije.

Sasvim je drugo pitanje nastojanje javnog mnjenja, koje se u određenim situacijama uvek uznemiri, da se iznađu krivci, pa se revolt, potpuno neopravdano i pogrešno često usmerava na organ starateljstva i radnike centra za socijalni rad. To je u stvari problem odnosa između primarne i drugih nivoa prevencije. U ovoj oblasti, da se podsetimo, reč je o punoletnim, poslovno sposobnim građanima i bez njihove saradnje članova porodične grupe, organu starateljstva nisu uvek dostupne potrebne informacije.

Uzimajući u obzir sve navedene okolnosti, u otvorenoj zaštiti možemo govoriti najčešće o primeni i realizovanju drugog nivoa principa blagovremenosti. Najpoželjniji nivo realizacije ovoga principa je samo onda kada su informacije, neophodne za preduzimanje adekvatnog tretmana, pravovremene i valjane i kada je priroda problema ili ispada funkcija takva da se može postići „vraćanje u prvobitno stanje“ tj. da se može ostvariti osnovni cilj zaštite. Najčešće se ovde radi o poremećenim porodičnim odnosima.

Princip potpunosti. Primenu i realizaciju principa potpunosti vezujemo za ostvarenje cilja, kao i za postojeće mogućnosti. To znači da se svako nastojanje, u praksi, mora rukovoditi, s jedne strane, postojećim stanjem stvari utvrđen dijagnostičkim zaključkom i planom zaštite, a sa druge strane, objektivnim i subjektivnim parametrima sistema zaštite. Ovi parametri zaštite u mnogome zavise od unutrašnje i spoljašnje organizacije rada centra za socijalni rad, od postignute zaštite, izuzetno zavise od razvijenosti dobrovoljnog socijalnog rada. Stoga je aksiom da bez dobro organizovanog dobrovoljnog socijalnog rada, u otvorenoj zaštiti princip potpunosti nije moguće ostvariti. Pošto od adekvatne primene ovoga principa u mnogome zavisi ostvarenje cilja a ujedno i trajanje angažovanja centra za socijalni rad u okviru otvorene zaštite, to model tretmana mora, pre svega, da se oslanja na spoljnu organizaciju rada centra. U radu centra za socijalni rad važi opšte pravilo da sa što manjim i što kraćim angažovanjem postigne opšti cilj ili ciljeve zaštite. Iz ovih razloga princip blagovremenosti i princip potpunosti delovanja su u najtešnjoj povezanosti jer svaki gubitak u vremenu i svaka nepotpuna intervencija i akcija otežavaju 
ili onemogućavaju realizovanje ovog opšteg pravila. Na primer, nastajanje hroničnih stanja u sferi bilo kog statusa, za socijalni rad i sve druge pozvane subjekte zaštite u dugotrajna angažovanja sa znatno većim materijalnim i drugim ulaganima i uz to značajna smanjenja mogućnosti da se cilj, odnosno ciljevi zaštite postignu. Smatra se da je u oblasti zatvorene zaštite princip ispoštovan tj. da je taj oblik zaštite tako organizovan da omogućava ostvarenje ovog principa.

Princip neprekidnosti delovanja. Bez obzira da li je reč o otvorenoj ili zatvorenoj zaštiti, odnosno o bilo kom obliku zaštite, poštovanje principa neprekidnosti delovanja je neminovno. Izuzetak, razumljivo, predstavlja postizanje opšteg cilja. Suština valjane organizacije rada je u tome da se realizovanje ovog principa kad god i čim je pre moguće, u što većoj ili potpunoj meri prenese na izvršioce izvan centra za socijalni rad. Takvim načinom se, u najboljoj meri, postiže prethodno akcijom „što manje i što kraće“. U metodskom pogledu ovaj princip je zagarantovan samo u oblasti adekvatno ostvarenih prava i uz izvršenje valjanog plana zaštite. To znači da, centar za socijalni rad, pre svega, ostvaruje princip neprekidnosti delovanja izvršavanjem svoje uloge inicijatora, organizatora i koordinatora procesa zaštite.

\section{Prikaz nekih neželjenih pojava u praksi}

Kada se analiziraju rezultati organizovanja i realizovanja zaštite odraslih i starijih građana, dakle, kada se vrši analiza prakse, potrebno je imati u vidu neka prethodna pitanja. Problem motivacije se u ovoj analizi svrstava u jedno od najvažnijih prethodnih pitanja. Nju možemo podeliti u tri kvaliteta: pozitivnu, koja proističe iz osećanja pripadnosti, koja je izgrađena valjanim vaspitavanjem i ulaganjem u decu i srodnike i koja proističe iz vršenja službene funkcije; suprotnu, onu sa negativnim određenjima, koja, po pravilu, proističe iz negativnih investicija, lošeg vaspitanja i poremećenih odnosa i koju ne retko izaziva strah od starenja i smrti. Treći kvalitet, koji samo uslovno može da se tretira kao pozitivna motivacija, proističe iz zavisnosti ili koristoljublja. U razmerama ove motivacije srećemo sve vidove nevaljanog ponašanja, nedovoljne čovečnosti i različite oblike zloupotrebe. Najčešći objekti ovakvog interesovanja su pokretna i nepokretna imovina odraslog, odnosno starijeg čoveka. Ovakvim načinom, socio-ekonomski položaj osobe, o kojoj je reč, može značajno da utiče na prirodni proces starenja i opadanja psihofizičkih sposobnosti i funkcija i dolazi do povezanosti u kojoj mogu socio-ekonomski i psihofizički status međusobno da se kompromituju, da rivaliziraju i da se jedan javlja kao rušilac drugog statusa. Razumljivo, postoji mogućnost i ona je u pozitivnim primerima prakse realizovana da se ova dva statusa međusobno dopunjuju da sarađuju i time omogućavaju samostalnost, nezavisnost odrasloj odnosno ostareloj osobi. To znači, da vitalnost i očuvanost psihofizičkih funkcija mogu da kompenzuju slabiji socio-ekonomski status i obratno, da valjan socio-ekonomski status može otkloniti ili ublažiti neželjene posledice kompromitacije psihofizičkog statusa ili disfunkcije. Na primer, takav je slučaj kada se obezbeđuje valjana pomoć ili nega u kući, kada je zainteresovana osoba u mogućnosti da angažuje određene oblike pomoći u kući dopremanje hrane, štampe i tako dalje. Na ovaj način prvo pravilo u analizi rezultata prakse treba da bude povezivanje brige i staranja sa motivacijom i procena valjanosti te povezanosti. Ovo se odnosi kako na otvorenu tako i 
na domsku zaštitu. U kontekstu ovakvog razmatranja sledeće pravilo je obraćanje pažnje na poslovnu sposobno tj. mogućnost upravljanja svojom imovinom i svojim pravima i izvršavanju obaveza odnosno ocena rezultata starateljske zaštite. Jasno je da gubljenje poslovne sposobnosti isključuje valjanu primenu i korišćenje i socio-ekonomskog ali i u ostalim sferama očuvanog psihofizičkog statusa.

Postoji i relativno nezavisna motivacija, koju u načelu smatramo pozitivnom a na kojoj se zasniva dobrovoljni socijalni rad. Nju grade društveni ciljevi i društveni sistem vrednosti, opšti vaspitni i edukativni procesi ali i valjana organizacija lokalne i šire društvene zajednice. U njoj se stiču lični stav dobrovoljnog socijalnog radnika (u najširem značenju te reči) i društvena podrška i društvena verifikacija tog stava. Veoma značajno pitanje u oblasti ove motivacije predstavlja metodsko organizaciono rešenje, pre svega, lokacija ovog instituta. U našoj praksi, ovo osnovno pitanje je dobro rešeno, jer je postignut najbliži mogući odnos sa stanovišta prirodne sredine odraslog, odnosno ostarelog građanina. Dobrovoljni socijalni rad, mora biti „na dohvat ruke“ korisniku tih usluga. Međutim drugi aspekt ovog pitanja nije do kraja razvijen i razrešen. Nije još uvek postignut permanentan rastući trend regrutovanja i osposobljavanja dobrovoljnih socijalnih radnika u nivou potrebe. Dakle vrlo evidentne potencijalne mogućnosti, nisu za sada dovoljno iskorišćene. Ovo se pre svega može odnositi na angažovanje mladih i korišćenje njihove poletnosti i spremnosti za društveno koristan rad.

Drugo prethodno pitanje je vezano za materijalno organizacione mogućnosti društvene zajednice, kako u odnosu na postizanje željenog standarda živeljenja (u otvorenoj ili domskoj zaštiti) tako isto i u odnosu na razvoj adekvatnih oblika zaštite.

Treće prethodno pitanje za ocenu rezultata prakse je postignuta saradnja, po obimu i kvalitetu između konvergentnih oblasti i njihova otvorenost prema potrebama odraslih i starijih građana. Ovo pitanje se ustvari svodi na problem korišćenja društvenih mogućnosti.

Ako ova prethodna pitanja imamo u vidu onda procenu rezultata rada u oblasti socijalne zaštite moramo svodite na one propuste koji se u većoj meri mogu pripisati nekorišćenju postojećih mogućnosti i neizvršavanju službene dužnosti. Razume se, ovde je reč samo o nekim neželjenim pojavama u praksi jer je cilj ovog metodskog uputstva - otklanjanje i smanjivanje neželjenih efekata. U centru za socijalni rad u Beogradu nedovoljno je pažnje poklonjeno motivaciji radnika ili bolje reći afinitetu radnika za obavljanje određenih poslova i radnih zadataka. Nasuprot tome u stručnim krugovima je dobro poznata činjenica da pojedini izvršioci poslova nemaju afinitet za rad sa starijim građanima. Ovo pitanje može da izgleda kao preterivanje u postavljanju zahteva pred izvršioce poslova organa starateljstva kao nekakvo stručno pravilo za buduća vremena, ali to je činjenica koju ćemo pre ili posle morati da uvažavamo. Ovo pitanje je još neuporedivo važnije za domski smeštaj, odnosno na izbor kadrova koji su neposredno i tokom celog radnog vremena usmereni na zaštitu starijih građana.

Sa stanovišta organizacije rada u centru za socijalni rad veliku slabost predstavlja nekompletan timski rad. Ova nije rezultat samo objektivnih kadrovskih mogućnosti već pre svega posledica jedne prakse koju treba izmeniti. Razumljivo praksa se ne može valjano usmeriti bez izmene i dopune određenih stavova i ideacije o potrebama starijih građana. Veoma sporo se prihvata stav o potrebi učešća pedagoga i psihologa centra u timu koji se angažuju na organizovanju i realizovanju zaštite starijih građana. To je razume se rezultat rada u okviru zahteva u situaciji već značajno izraženog problema i mogli bismo reći onog već spomenutog preuzimanje brige kada je to neminovno. 
Nedovoljnosti su pre svega u oskudnom rezultatu dijagnostičkog postupka koji je i tako sužen, usmeren po pravilu samo na utvrđivanje i razmatranje dominantnog problema kako je on prezentovan u momentu značajne manifestacije i otkrivanja. Iz ovoga neminovno sledi lanac nedovoljnosti koji se proteže preko odsustva valjanog (ili bilo kakvog) plana zaštite do smeštaja gde i kada ima mesta.

Ova praksa se po pravilu obrazlaže, tumači i opravdava navodnom urgentnošću rada, odsustvom potrebnog vremena jer je reč o „hitnom slučaju“. Svakako ovde ne možemo govoriti o primeni principa blagovremenosti niti o principu potpunosti delovanja. Za ovakve neželjene pojave u praksi ne možemo okriviti samo centar za socijalni rad.

Otpust sa lečenja kada interes odraslog ili starijeg pacijenta zahteva saradnju i angažovanje socijalne zaštite mora biti planiran. Planiranje otpusta odnosno saradnja se najbolje postiže prilikom smeštaja bilo da je reč o lečenju ili rehabilitaciji. Ovu digresiju činimo samo zato što je saradnja sa zdravstvom u zaštiti odraslih i starijih građana izuzetno značajna.

Iz ovih razloga potrebno je obezbediti mogućnosti za organizovanje i realizovanje zaštite pre nego što se stvore uslovi za neodložno i suženo reagovanje.

Kada je reč o primeni instituta starateljstva i organizovanju starateljske zaštite važna pitanja su stvaranje dijagnostične osnove za opredeljenje delimično ili potpuno lišavanje poslovne sposobnosti i procena motivacije potencijalnih staralaca. Sa stanovišta ostvarenja opšteg cilja važna je procena postignutih uslova za delimično ili potpuno vraćanje poslovne sposobnosti. U praksi u Beogradu o ovome se još uvek ne vodi dovoljno računa. Ograničen postojećim okolnostima organ starateljstva nije uvek u mogućnosti da zaoštrava pitanje podobnosti potencijalnost staraoca jer je jedina alternativa neposredno starateljstvo. Mada je ovo najnepoželjniji vid starateljske zaštite čak i u nekim aspektima donekle sporan on u Beogradu beleži rastući trend. Ako potražimo razloge ovakvom stanju stvari nalazimo sa jedne strane odsustvo valjane motivacije uopšte, a sa druge, sindrom obaveza za staraoca bez odgovarajuće primene inače omogućenih društvenih priznanja.

Prirodni proces starenja i pad psihofizičkog statusa i njegovih funkcija kao prirodna posledica, pre ili posle neminovno iziskuje društvenu brigu i društvenu zaštitu. ${ }^{3}$ Ona je usmerena na sve statuse, ali u praksi postoji ataksija zadovoljavanja potreba a i zapostavljanje određenih aspekata potreba. U tim slučajevima u nedozvoljenoj meri je zapostavljeno poštovanje principa potpunosti delovanja. To se najčešće odnosi na poštovanje ličnosti korisnika usluga i realizovanje ili očuvanje njegovih pojedinih prava. Raspolaganje penzijom smeštenog korisnika, sa jedne strane, opterećuje centar za socijalni rad, a sa druge, sužava prava korisnika usluga. Sličan je slučaj sa pokretnom imovinom koja se neprofesionalno popisuje i procenjuje, jer za to nisu obezbeđeni potrebni uslovi. To je uvek veoma skup postupak. On traži poznavanje predmeta popisa i procene na nivou nalaza veštaka, za šta, kao što je već rečeno, ni približno nisu stvoreni uslovi. Tako se na primer jedna umetnička slika veće ili velike vrednosti može popisati kao „slika“ sa ili bez oznake formata ili autora. Problem korišćenja stana, kad odlaskom nosioca stanarskog prava u dom, on ostaje prazan, nije razrešen. Neretko se događa da centar za socijalni rad doplaćuje ili u potpunosti snosi cenu smeštaja a da stan korisnika ostaje prazan i zaključan. To je paradoks o čijem se društvenom značaju može govoriti valjano ako se na nivou grada sagleda ukupan broj ovakvih slučajeva i situacija.

\footnotetext{
${ }^{3}$ Izuzev u slučaju valjane porodične zaštite.
} 
Mada su ova nabrajanja samo prethodna pitanja tretmana, vezana za dijagnostički postupak, zaključak i plan zaštite, ona veoma bitno utiče na status korisnika usluga i često onemogućavaju valjan tretman. U odnosu na praćenje, praksu karakteriše razmatranje celishodnosti uvedenog prava, tj. obustava ili nastavljanje delovanja tog prava. Bolje rečeno, aktivnost se svodi na oskudnu procenu uslova za nastavljanje ili obustavu prava. Kao što je napomenuto zajednički plan zaštite organa starateljstva i stručnih predstavnika doma u koji se smešta ili je smešten korisnik usluga je prava retkost.

Otpust korisnika se planira, a o premeštaju odlučuje stručna služba određenog doma uz naknadno pribavljanje saglasnosti organa starateljstva.

Ovu prilično tmurnu sliku prakse dalje otežava podatak da se prečesto događa da dom ispostavlja fakture, centar ih isplaćuje, a da je korisnik usluga "davno napustio dom“.

$\mathrm{U}$ oblasti otvorene zaštite rezultati se situiraju oko pojedinačnih ciljeva i navedeni principi zaštite nisu u valjanoj meri ispoštovani. Samim tim i opšti cilj se, po pravilu, ne planira, pa je realizacija zaštite svedena na pojedina pitanja određenih statusa. Najčešće je reč o ostvarivanju određenog prava i korišćenju nekih oblika rada dnevnih centara. Kao što je napomenuto dobrovoljni socijalni rad nije u ovoj oblasti dovoljno razvijen i nije podignut na nivo valjane organizacije ili sistema. Praćenje statusa korisnika u otvorenoj zaštiti je svedeno na reviziju ostvarenih prava sa već opisanim obimom, sadržajem i kvalitetom rada.

Na kraju izlaganja o nekim nepovoljnim rezultatima prakse, treba napomenuti da se tek sada, preko rezultata istraživanja, stvaraju uslovi za utvrđivanje potreba starijih građana, ali još uvek samo na nivou opština, sa delimičnim osnovama za uže lociranje potreba i reagovanja na njih.

\section{Dijagnostički postupak}

Svakoj klasifikaciji i podeli, pa time i ovoj, koja je primenjena u radu, može se prigovoriti da u praksi ne postoje „čisti slučajevi“, odnosno, homogene situacije. Ako se ovakav prigovor pokuša ugraditi u metodiku rada, uz sva uvažavanja razloga na kojima se on može zasnivati, opšti rezultat je zbrka koja dalje vodi u nedovoljnu određenost, stručne kompromise, pa time i u proizvoljnost. Kada je, dakle, reč o profesionalnom angažovanju socijalne zaštite na utvrđivanju potreba i načina zadovoljavanja tih potreba i izvršenju zakonskih obaveza organa starateljstva, polazno stanovište je dominantni problem i hijerarhija potreba. Ovo polazište se nužno sukobljava sa stavom koji se naročito u praksi zagovara, a sreće i u izlaganjima pojedinih stručnjaka, koji se bave teorijskim pitanjima iz ove oblasti, o obavezi i potrebi da se sagleda "Sveukupnost“ življenja i potreba. Ako bismo prihvatili ovakvo stanovište, nužno bismo doveli u pitanje svaki dijagnostički postupak i svaki dijagnostički zaključak u kratkom vremenskom intervalu s obzirom na tempo i trend mogućeg razvoja disfunkcije. To bi i dalje nužno odvodilo u dijagnostiku radi dijagnostike jer, kao što je dobro poznato, registar mera, usluga i oblika socijalne zaštite je ne samo konačan, nego i veoma ograničen. Ovo, pre svega, u oblasti otvorene zaštite. Dom, kao što je poznato, raspolaže ili bi morao da raspolaže valjanim mehanizmom neposrednog i permanentnog praćenja i reagovanja na promenu potreba.

Ovaj predgovor treba da obrazloži značajno sužavanje nekih sadržaja dijagnostičkog postupka koji se ovom prilikom preporučuje:

- Utvrđivanje lišenosti porodičnog staranja,

- Utvrđivanje stepena i vrste egzistencijalne ugroženosti,

- Utvrđivanje stepena neodložnosti angažovanja - reagovanja,

- Konkretizacija svih utvrđivanih statusa i oblasti njihovog kompenzovanja, 
- Utvrđivanje osnovnog oblika zaštite, predikcija njegovog trajanja i aktivnosti organa starateljstva za vreme njegovog trajanja (priprema primene konvergentnih oblika, mera i usluga zaštite),

- Obrazloženje izbora osnovnog oblika zaštite kao i razloga zbog kojih nisu, kao osnovni oblik zaštite, korišćeni ostali primenljivi oblici,

- Određivanje modela neophodnih pratećih oblika, mera i usluga zaštite,

- Određivanje izvršilaca i modela saradnje,

- Okvirna dinamika rada.

Kada se uporede skice dijagnostičkog postupka, koji se preporučuju u postupku zaštite dece bez roditeljskog staranja i odraslih i starih bez staranja njihove odrasle dece, odnosno porodičnog staranja, može se zaključiti da je konstrukt identičan. Međutim, osnovni elementi pojedinih sadržaja, a i metodika pretrage se razlikuje. Tako npr. značajna ograničenja mogu da slede zbog kompromitacija funkcija čula, izvesne karakteristične sumnjičavosti i prepokrivenosti posebnom motivacijom ili posebnim interesom.

Osnovni rezultat dijagnostičkog postupka pa time i skice dijagnostičkog osnova treba da raščisti dva pitanja. Prvo, koje se odnosi na poslovnu sposobnost i samovlast korisnika usluga i drugo - da, shodno dominantnom problemu, smer daljih akcija usmeri na otvorenu ili domsku zaštitu. U opredeljenju za otvorenu zaštitu, suštinu akcije predstavlja organizacija lokalne zajednice i adekvatno korišćenje preostalih sposobnosti, a kod drugog opredeljenja, izbor određenog doma koji sa stanovišta organizacije rada i drugih parametara, može u najvećoj meri da zadovoljava potrebe korisnika. Ova čista dijagnostika zavisi od poštovanja principa blagovremenosti delovanja i „zatečenog stanja“ koje opet zavisi od psihofizičkog statusa korisnika usluga i valjanosti ranije brige koja se „preuzima“.

Iz navedenih razloga dijagnostički zaključak o obliku zaštite (otvorena ili domski smeštaj) po pravilu treba da bude situiran i zapisničkom izjavom korisnika usluga o konkretnom obliku zaštite. Međutim, i u slučaju angažovanja kompletnog tima stručnih radnika centra za socijalni rad nije uvek obezbeđen uslov - bez koga se ne može. Reč je, naime, o procenama psihofizičkog statusa koje mogu da izvrše valjano samo zdravstveni radnici. Zaključak se svodi na neophodnu saradnju sa zdravstvom. U protivnom, zaključak tima može da bude i nepouzdan i nevaljan. Kako je reč o postupku i proceduri koji mogu da potraju, ova preporuka ne dolazi u obzir za tzv. hitne slučajeve, odnosno gde je reagovanje neodložno. U zavisnosti od razvijenosti organizacije i pozitivnih efekata kućne nege, u značajnom broju slučajeva zavisi veličina ovog manevarskog prostora.

Nije teško utvrditi potpuno odsustvo porodičnog staranja. Problem je odrediti stvarni interes i stvarnu valjanost formalno postojeće zaštite. Ovo, pre svega, u funkciji motivacije. Kada se ovaj zadatak valjano obavi, uz procenu psihofizičkog statusa i utvrđivanje stava korisnika usluga, stvaraju se potrebni uslovi i za izbor osnovnog oblika zaštite.

Utvrđivanje stepena i vrste egzistencijalne ugroženosti određuje i stepen neodložnosti reagovanja. Kada je tim stručnih radnika kompletan i kada je obezbeđeno potrebno iskustvo radnika, zadovoljavanje ovog zahteva nije naročito težak stručni zadatak. Razumljivo, ovde su usluge zdravstva i medicinske dijagnostike indikovane.

Analizom i sintezom podataka koji se odnose na aktuelizovane statuse, odnosno deficite u tim oblastima, dolazi se do osnova za zaključivanje o mogućoj realizaciji opšteg cilja, odnosno do svođenja aspiracija zaštite na nivo posebnih i pojedinačnih ciljeva zaštite.

Svi ostali elementi skice dijagnostičkog rezultata proističu i zasnivaju se na ovim, prethodno razjašnjenim i utvrđenim, alinejama postupka. 


\section{Izbor osnovnog oblika zaštite}

Prilikom opredeljivanja za izbor osnovnog oblika zaštite, korisno je imati u vidu sledeću klasifikaciju uslova i uzroka odsustva porodičnog staranja:

1. Odrasli i stariji bez dece-srodnika obaveznih da se staraju o njima (obaveznih na izdržavanje);

2. Odrasli i stari sa decom-srodnicima obaveznim na staranje - lišeni porodičnog staranja;

3. Odrasli i stariji sa decom-srodnicima obaveznim na staranje, sprečenih da vrše dužnost staranja.

U prvom slučaju, ukoliko to ostale pretpostavke dopuštaju ${ }^{4}$, nastojanje je usmereno na što duži boravak u prirodnoj sredini. Alternativa je smeštaj u dom.

$\mathrm{U}$ drugom slučaju, kada to prethodna pitanja dopuštaju, osnovni oblik zaštite, ako je usmeren na otvorenu zaštitu, se odnosi na izmenu stavova, otklanjanje poremećenih porodičnih odnosa ili kompenzovanje staranja valjanom organizacijom lokalne zajednice. Alternativa je domski smeštaj.

U trećem slučaju, u zavisnosti od određenosti i trajanja te objektivne sprečenosti, preuzimanje brige može da bude privremenog ili trajnog karaktera. Osnovni oblik zaštite u funkciji navedenih oblika sprečenosti, utvrđuje se prema ideaciji opisanoj u prvom slučaju.

$\mathrm{U}$ kontekstu blagovremenog postupanja, načelo zaštite u ovom slučaju je da je osnovni oblik zaštite uvek sadržan u otvorenoj zaštiti. Tada je moguće govoriti o domskom smeštaju kao privremenom obliku zaštite. U takvom viđenju uloge organa starateljstva, prethodno pitanje je isključivo stav korisnika usluga.

Primena instituta starateljstva predstavlja meru zaštite, pa se iz tog razloga i ne diskutuje o njemu kao o osnovnom obliku zaštite.

\section{Specifičnosti plana zaštite}

Pored zahteva da plan zaštite bude sačinjen u saradnji sa svim nosiocima zaštite, odnosno, predstavnicima zaštite, svaki plan ima dve opšte specifičnosti: opštiju, koja je opredeljena otvorenom, ili domskom zaštitom i posebnu, koju određuje priroda slučaja i splet mogućnosti u datom lokalitetu. Kod izrade plana domske zaštite posebnost ili specifičnost se odnosi na očuvanje povezanosti sa prirodnom sredinom i planiranje premeštaja i otpusta.

Specifičnost plana otvorene zaštite, u odnosu na opštu šemu plana zaštite, su u tome da se izvršenje, pre svega, temelji na dobrovoljnom socijalnom radu, kada izostaju emocionalna i funkcionalna uporišta porodične grupe. $U$ oblasti otvorene zaštite odraslih i starih građana uvek postoji rizik od ozbiljnijeg slabljenja ili gubitka poslovne sposobnosti. Kako za ovu oblast otvorene zaštite vredi pravilo „što manje i što kraće“ angažovanje organa starateljstva, to prevencija ovo rizika, takođe, predstavlja specifičnost plana zaštite.

\footnotetext{
${ }^{4}$ Misli se na psihofizički status korisnika i njegove stavove.
} 


\section{Model tretmana}

Kao u slučaju organizovanja i realizovanja zaštite dece i omladine bez roditeljskog staranja i zaštita odraslih i starijih građana bez porodičnog staranja je složen društveni i profesionalni zadatak. Po pravilu, on je visoko situiran rizicima svih statusa i za čije valjano izvršenje je potrebna saradnja sa konvergentnim oblastima a posebno sa zdravstvom i dobrovoljnim socijalnim radom.

Ostvarenje opšteg cilja koji postižemo valjanim planiranjem, poštovanjem istaknutih principa zaštite i samo u otvorenoj zaštiti, u slučajevima kada nije prisutno neko od realizovanih prava o kojima odlučuje organ starateljstva, zavisi i od modela tretmana, odnosno usluga. Postupanjem u okviru zahteva, to jest reagovanjem samo u odnosu na prezentovani problem ili situaciju, po pravilu nije moguće postići opšti cilj. Kako je ovo upravo jedno od osnovnih obeležja prakse, nije realno očekivati, da se samo poštovanjem preporuka ovog metodskog uputstva, situacija bitnije izmeni i stvore uslove za ostvarenje pomoći od samopomoći. Ukoliko se u postupku planiranja rada centra za socijalni rad ne učine značajne i bitne novine i proširenja i ukoliko konvergentne oblasti preko svojih predstavnika ne učestvuju u izradi i realizaciji takvog plana rada centra, verovatnije je da će tok stvari ostati isti, nego da će se menjati.

Sa svega izloženog, osnovni smisao tretmana je usmeren na organizovanje lokalne zajednice. Da bi se to postiglo osnovni oblik zaštite, kako je to već istaknuto, je definisan prirodnim prostorom u kome žive odrasli, odnosno stariji korisnik usluga. Svi ostali aktivnosti aspekti su samo deo ovog rešenja.

\section{Osnovni oblik zaštite i model usluge}

U zaštiti odraslih i starijih građana bez porodičnog staranja, osnovna podela oblika zaštite vrši se prema realizaciji svih, u registru, postojećih oblika, mera i usluga, u prirodnoj sredini ili institucijama socijalne zaštite. Dakle, govorimo o otvorenoj i domskoj zaštiti kao o osnovnim oblicima zaštite. To, u stvari, znači skup svih oblika, mera i usluga primenjivih u prirodnoj sredini korisnika ili domskoj zaštiti.

Kada smo se opredelili da se zaštita organizuje i realizuje u otvorenoj zaštiti model tretmana je sledeći:

Kompenzovanje socio - ekonomskog statusa

I Materijalne usluge:

- Osnovne novčane naknade,

- Povremene novčane naknade,

- Materijalne naknade pod izuzetnim uslovima,

- Novčane pomoći u vidu pozajmice,

- Dodatak za tuđu pomoć i negu.

Saglasno pretpostavljenom cilju zaštite u oblasti pružanja materijalnih usluga, razlikujemo kompenzovanje socio-ekonomskog statusa bez osnovne novčane naknade i dodataka za tuđu pomoć i negu od kompenzovanja tog statusa primenom i ovih materijalnih usluga. To znači da se postizanje opšteg cilja odvija baz navedenih materijalnih usluga. 
Međutim, uslov da pružanje materijalne naknade pod izuzetnim uslovima bude vremenski ograničeno, to jest određeno otklanjanjem „trenutnog“ ispada statusa, koje nije moguće prevazići povremenim novčanim naknadama ili pozajmicama. U posebnim prilikama moguće je u tretman, koji je usmeren ka opštem cilju, uvrstiti i dodaz za tuđu pomoć i negu do postizanja svrhe rehabilitacije.

II Usluge posredovanja u okviru drugih delatnosti:

- Rešavanje stambenog problema,

- Zapošljavanje,

- Upućivanje na osposobljavanje,

- Uključivanje u dnevne centre,

- Angažovanje zdravstvenih ustanova,

- Obezbeđenje kućne nege i pomoći u stanu,

- Korišćenje sredstava alimentacionih fondova i fondova solidarnosti,

- Korišćenje usluga različitih RO u slučaju privremene sprečenosti dece odnosno srodnika i

- Letovanje-zimovanje (odmor i rekreacija).

Sa stanovišta postizanja opšteg i posebnih-pojedinačnih ciljeva izuzetno važna oblast angažovanja organa starateljstva je definisana ostvarenjem prava van domašaja ovlašćenja centra za socijalni rad. Reč je o penziono-invalidskom i zdravstvenom osiguranju i ostvarivanju prava na penziju, rešavanje stambenog pitanja, lečenje i rehabilitaciju. Ostvarivanjem ovih prava postiče se i prethodno pitanje za ostvarivanje pomoći do samopomoći, što je, u ne malo broju slučajeva, i zadovoljavanje opšteg cilja.

III Nematerijalne usluge:

- Usluge savetovanja i

- Vršenje nadzora nad obavljanjem starateljske dužnosti.

Nematerijalne usluge koje se, u ovom slučaju, odnose na savetodavni rad i savetodavne usluge, a u vezi sa socio-ekonomskim statusom, indikovani su, po pravilu, u razmerama porodične, srodničke grupe, kada je reč o izdržavanju. Ovo i u vezi sa pružanjem, ali isto tako sa prihvatanjem izdržavanja.

Nadzor nad radom staraoca, naročito u vezi sa raspolaganjem imovinom korisnika usluga predstavlja važan zadatak organa starateljstva koji se obavlja u kontinuitetu sa ocenom izrečenom obično u reviziji.

Kompenzovanje pravnog statusa

I Nematerijalne usluge:

- Vršenje nadzora,

- Pravna pomoć,

- Neposredno starateljstvo,

- Aktivno prisustvovanje,

- Zastupanje,

- Pokretanje i vođenje postupka po službenoj dužnosti.

II Usluge posredovanja:

- Mišljenje, predlog OUR-ima socijalne zaštite,

- Mišljenje i predlog suda,

- Učešće u radu suda,

- Ostvarivanje prava, 
- Zahtev za izvršenje rešenja organa starateljstva,

- Poveravanje dužnosti staraoca društveno - pravnom licu,

- Pomoć u vršenju starateljske dužnosti.

Kompenzovanje psihofizičkog statusa

I Nematerijalne usluge:

- Savetovanje,

- Vršenje nadzora.

II Usluge posredovanja:

- Uključivanje u savetovalište,

- Uključivanje na lečenje

- Uključivanje u OUR-e socijalne zaštite,

- Uključivanje na osposobljavanje.

Kompenzovanje vaspitno-obrazovnog statusa

I Nematerijalne usluge:

- Savetovanje,

- Vršenje nadzora.

II Usluge posredovanja:

- Uključivanje u savetovalište,

- Smeštaj u druge organizacije socijalne zaštite,

- Uključivanje na osposobljavanje,

- Letovanje-zimovanje (odmor, rekreacija i slobodno vreme).

$U$ realizovanju ovog modela usluga ne podrazumeva se učestvovanje samo profesionalnih stručnih radnika nego i angažovanje dobrovoljnog socijalnog rada. Kako je reč o kompleksnoj metodi organizovanja lokalne zajednice ovo pitanje ne sužavamo na model usluga, nego će poseban odeljak tretirati ovu problematiku.

Kada smo se opredelili da se zaštita organizuje i realizuje u domskoj zaštiti, model usluga u tretmanu se zasniva na pretpostavci da su sva prethodna pitanja smeštaja adekvatno rešena. Na taj način se tretman sužava na izvesne netipične situacije, odnosno, one koje nisu karakteristične za većinu korisnika usluga domske zaštite - kada je reč o socioekonomskom i pravnom statusu.

Smisao tretmana u centru za socijalni rad je uvek usmeren na uspostavljanje i očuvanje, odnosno razvoj povezanosti sa prirodnom sredinom korisnika usluga, zatim na premeštaj i otpust, kada je to u interesu korisnika usluga. Usklađivanje prava i opravdanih očekivanja korisnika doma sa pružanjem domskih usluga je takođe važna oblast u kojoj se tretman odvija. S obzirom na prirodu ovih interesa korisnika, nematerijalne usluge i usluge posredovanja su, po pravilu, češće od materijalnih usluga.

I Nematerijalne usluge:

- Savetovanje,

- Vršenje nadzora,

- Pravna pomoć,

- Neposredno starateljstvo,

- Svečani čin,

- Poseta korisniku,

- Zastupanje,

- Izveštavanje, 
- Pokretanje i vođenje postupka po službenoj dužnosti,

- Poseta radne organizacije.

II Usluge posredovanja:

- Neposredna realizacija domskog smeštaja,

- Materijalna naknada,

- Rešavanje stambenog problema,

- Uključivanje na letovanje - zimovanje,

- Mišljenje i predlog suda,

- Mišljenje i predlog,

- Ostvarivanje prava,

- Učešće u radu suda,

- Zahtevi za izvršenje organa starateljstva,

- Poveravanje dužnosti staraoca društveno - pravnom licu i

- Pomoć u vršenju starateljske dužnosti.

III Materijalne usluge:

- Povremene novčane naknade,

- Pozajmice.

\section{Zaključak}

Odsustvo porodičnog staranja je veoma složen problem sa implikacijom socio-psihološke prirode koje mogu imati trajan uticaj na celokupan život svake osobe. To daje poseban značaj stručnom socijalnom radu pri čemu se posebno ističu sledeći zadaci:

- Rano utvrđivanje lišenosti porodičnog staranja, stepena ugroženosti i hitnosti reagovanja;

- Izbor osnovnog oblika zaštite, predikacije trajanja i shodno tome angažovanje organa starateljstva i stručnog tima u izboru odgovarajućih metoda i tehnika rada.

Krajnji cilj zaštite je osposobljavanje pojedinca da može, u skladu sa svojim psiho fizičkim potencijalima, relativno skladno funkcionisati u socijalnoj sredini. Kod dece i omladine, prevashodni je cilj povratak u primarnu porodicu.

\section{Literatura}

Burić, O.: Porodica i društveni sistem, Institut za socijalnu politiku, Beograd, 1980.

Veljić, M.: Socijalna struktura porodice i dečija zaštita, Zavod za proučavanje socijalnih problema, Beograd, 1980.

Vidanović, I.: U susret životu - monografija, Naučno - istraživački Centar za socijalni rad i socijalnu politiku FPN, Beograd, 1996.

Milanović, M.: Socijalni rad u ustanovama socijalne zaštite, Udruženje stručnih radnika socijalne zaštite i Savez društva socijalnih radnika Srbije, Beograd, 1995.

Obreković, M.: Roditeljsko pravo i socijalna zaštita, VŠSR, Beograd, 1988.

Uputstva o organizaciji i radu službe socijalne zaštite Gradskog Centra za socijalni rad Beograd-1991. 